\title{
Abordagem da doença renal crônica na formação do técnico de enfermagem: enfoque na prevençáo
}

Approach to chronic kidney disease in the training of the nursing technician: a focus on prevention

\section{RESUMO}

O envelhecimento da população com consequente surgimento de doenças crônicas é uma realidade no Brasil, fato esse que pode ser observado nos indicadores de morbidade e mortalidade por doenças crônico-degenerativas. A doença renal crônica está entre as principais complicaçôes do diabetes mellitus e hipertensão arterial sistêmica, sendo esses dois agravos os responsáveis por cerca de $90 \%$ da demanda de programa de diálise como terapia renal substitutiva. Nesse sentido, o projeto de extensão "Abordagem da doença renal crônica na formação do técnico de enfermagem: enfoque na prevençáo" foi relevante por fornecer, por meio de palestras educativas, orientaçóes e preparo ao futuro técnico de enfermagem quanto à prevenção da doença renal crônica e promoção da saúde renal. É importante salientar que esse profissional tem um papel relevante na disseminação da informação e conscientização da população, visto que atuará nas diversas modalidades de assistência à saúde da comunidade, desde a atenção primária até o atendimento de alta complexidade.

Palavras-chave: Doença renal crônica. Educação em saúde. Prevenção.

\section{ABSTRACT}

The aging of the population with consequent emergence of chronic diseases is a reality in Brazil, a fact that can be observed in the indicators of morbidity and mortality due to chronic-degenerative diseases. Chronic kidney disease is one of the main complications of diabetes mellitus and systemic arterial hypertension, and these two diseases are responsible for about $90 \%$ of the demand for a dialysis program as kidney replacement therapy. In this sense, the extension project "Chronic kidney disease approach in the training of the nursing technician: a focus on prevention" was relevant for providing, through educational lectures, guidelines and preparation for the
Adriana Lemos de Sousa Neto

Mestre em Atenção à Saúde pela Universidade Federal do Triângulo Mineiro, Minas Gerais, Brasil; professora efetiva na Escola Técnica de Saúde da Universidade Federal de Uberlândia, Minas Gerais, Brasil (adrianasneto@ ufu.br).

Karla Benetti Andrade Ortelan

Graduanda em Enfermagem na Universidade Federal de Uberlândia, Minas Gerais, Brasil (karlinhaortelan@ gmail.com).

Natalia Rosa e Souza

Especialista em Saúde do Adulto pela Universidade Federal do Triângulo Mineiro, Minas Gerais, Brasil; professora substituta na Escola Técnica de Saúde da Universidade Federal de Uberlândia, Minas Gerais, Brasil; membro do Grupo de Pesquisa em Educação e Saúde (GPES/UFU) (natalia.r.souza@hotmail. com).

Tássia Alves da Silva

Graduanda em Enfermagem na Universidade Federal de Uberlândia, Minas Gerais, Brasil (tassiaalves2010@ hotmail.com). 
future nursing technician regarding the prevention of the disease renal and renal health promotion. It is important to point out that the future nursing technician has a relevant role in the dissemination of information and awareness of the population, since it will act in the various health care modalities of the community, from primary care to highly complex care.

Keywords: Chronic kidney disease. Health education. Prevention.

\section{INTRODUÇÃO}

Atualmente observa-se um aumento progressivo das Doenças Crônicas não Transmissíveis (DCNT), as quais já são reconhecidas como um problema de saúde global (SCHMIDT et al., 2011). Dentre as DCNT, a Doença Renal Crônica (DRC) apresenta-se como importante problema de saúde pública, devido aos altos gastos com o seu tratamento, o aumento da prevalência e incidência e as altas taxas de morbimortalidade (SESSO et al., 2011).

A insuficiência renal ocorre quando os rins são incapazes de remover água, eletrólitos e escórias metabólicas do organismo, podendo ser aguda ou crônica. A aguda tem início súbito e é com frequência reversível, enquanto a insuficiência renal crônica se manifesta gradativa e silenciosamente, mas também pode ocorrer como resultado de um episódio agudo precedente (ZANQUETTA et al., 2009).

Apesar de silenciosa, a DRC pode manifestar sinais e sintomas e a sua intensidade será relativa ao grau do comprometimento renal e da presença de outras comorbidades (MIRANZI et al., 2011). Aos indivíduos que se encontram em estágio final da doença, são oferecidos como tratamentos as Terapias Renais Substitutivas (TRS): diálise peritoneal, hemodiálise e transplante renal (RUDNICKI, 2014).

O avanço da doença renal e o tratamento dialítico causam limitaçóes e problemas em relação à saúde física, psicológica e funcional do doente (MIRANZI et al., 2011). Dessa forma, o indivíduo com DRC requer atenção especial, sendo relevante o diagnóstico precoce seguido de condutas terapêuticas apropriadas (BASTOS et al., 2009).

É perceptível a necessidade de um acompanhamento interdisciplinar 
aos pacientes com DRC. Nesse sentido, destaca-se o papel do enfermeiro na integração dos demais membros da equipe, em especial o técnico de enfermagem, para planejar açóes e campanhas educativas entre os usuários dos serviços de saúde e seus familiares. Destaca-se assim, a importância da educação em saúde como estratégia fundamental na prevenção de doenças e promoção da saúde (MIRANZI et al., 2011).

Considerando a relevância da equipe de enfermagem, em especial do técnico de enfermagem no atendimento ao doente renal, é importante o aperfeiçoamento e a capacitação constantes desses profissionais, sobretudo os que atuam nessa área, a fim de que estejam aptos a proporcionar melhor qualidade de vida ao paciente e sanar suas dúvidas relacionadas à sua condição de saúde (RODRIGUES; BOTTI, 2009). Nesse sentido é importante frisar que o enfermeiro tem grande relevância no ato educativo dos técnicos, auxiliares de enfermagem e da comunidade em geral (DUARTE; BORGES; ARRUDA, 2011).

Ações de extensão têm se mostrado importantes alternativas para oferecer conhecimento e informações para a população sobre DRC, assim como na formação de profissionais de saúde (BORBA; MELO; LELIS, 2011). Apesar disso, poucos trabalhos de extensão têm focado na formação do profissional de enfermagem e no paciente. Os profissionais de enfermagem têm relatado, em alguns casos, déficit de conhecimento, contudo, também interesse em participar de treinamentos e ou capacitações (SCHREIDER; FERNANDES, 2015).

Nessa perspectiva, foi criado, no âmbito da Escola Técnica de Saúde (ESTES) da Universidade Federal de Uberlândia (UFU), o projeto de extensão "Abordagem da doença renal crônica na formação do técnico de enfermagem: enfoque na prevenção", cujos objetivos foram, além de abordar o tema descrito junto aos alunos dos cursos técnicos de enfermagem: a) realizar palestras nas escolas técnicas com o tema doença renal crônica, com enfoque na prevenção; b) contribuir para a formação profissional dos alunos dos cursos técnicos de enfermagem de Uberlândia; c) envolver alunos da graduaçáo de enfermagem da UFU e alunos do ensino profissionalizante, permeando a troca de saberes e o despertar para a prevenção da doença renal crônica; d) 
conscientizar os futuros técnicos de enfermagem sobre a importância de seu papel na educação em saúde e na orientação da população sobre prevenção da doença renal.

\section{METODOLOGIA}

O projeto de extensão "Abordagem da Doença Renal Crônica na formação do técnico de enfermagem: enfoque na prevenção" foi proposto por docentes da ESTES/UFU e duas acadêmicas do $8^{\circ}$ período do curso de graduação em enfermagem da UFU. Apesar de não estar vinculado a nenhum programa e/ou instituição de fomento, a atividade extensionista foi cadastrada com parecer favorável no Sistema de Informação de Extensão (SIEX/UFU), mediante registro 15228.

O projeto foi realizado no período de janeiro a julho de 2017 e consistiu na oferta de palestras expositivas que abordaram os aspectos gerais da DRC, como: definição, epidemiologia, grupos de risco, critérios para diagnóstico e classificação, modalidades de tratamento e prevenção.

As docentes envolvidas no projeto são especialistas em Enfermagem em Nefrologia e, durante o acompanhamento de discentes nas aulas práticas realizadas no Hospital de Clínicas (HC/UFU), conheceram as duas acadêmicas que estagiavam na área da Nefrologia. Nesse contato e, a partir da demanda de atendimentos da equipe de enfermagem a clientes com doença renal e da carência de informaçóes acerca do tema nas grades curriculares dos cursos técnicos de enfermagem, surgiu a ideia de elaboração de um projeto de extensão que abordasse o tema doença renal junto aos futuros técnicos de enfermagem. Cabe mencionar o papel de multiplicador que esse profissional exerce junto à população, considerando sua atuação na educação em saúde desde a atenção primária até os níveis de maior complexidade na assistência à saúde.

As instituições de ensino públicas e privadas da cidade de Uberlândia que fornecem curso técnico de enfermagem foram convidadas a participar do projeto por contato telefônico. De seis escolas que oferecem o curso, uma náo apresentou disponibilidade de horário para participação no projeto. Das escolas participantes foram 
obtidas declaraçôes de aceite de participação e coleta da assinatura dos diretores/coordenadores de curso das respectivas instituiçôes. A atividade não foi submetida para apreciação do Comitê de Ética em Pesquisa (CEP) por não abordar diretamente os alunos que assistiram às palestras.

Em visitas pré-agendadas foram realizadas palestras expositivas informativas e ilustrativas sobre o tema proposto aos alunos do $1^{\circ}$ ao $4^{\circ}$ período dos cursos técnicos de enfermagem.

As palestras foram ministradas pelas acadêmicas do $8^{\circ}$ período do curso de Graduaçáo em Enfermagem, participantes da equipe do projeto, sob a supervisão das duas docentes especialistas em Enfermagem em Nefrologia. Montou-se um cronograma de execução com duração de seis meses sendo que, quinzenalmente, as graduandas reuniamse com as docentes orientadoras para discussão sobre o preparo das palestras e organizaçáo dos materiais que seriam utilizados durante a realização do projeto.

Além disso, ao final das palestras foram distribuídos panfletos sobre o tema e apresentados os materiais de uso em hemodiálise (cateteres, linhas arteriais e venosas, filtros de polissulfona) e diálise peritoneal, materiais esses que pertencem ao HC/UFU e, por estarem fora do prazo de validade, são utilizados exclusivamente para aulas e demonstrações. Tais materiais foram emprestados para demonstração e posteriormente devolvidos ao HC. Houve também, após as palestras, o esclarecimento de dúvidas e discussão sobre o assunto entre os alunos dos cursos técnicos participantes e a equipe responsável pelo projeto de extensão.

\section{RESULTADOS E DISCUSSÃO}

Foram realizadas cinco palestras, sendo uma em cada escola participante. Participaram do projeto 209 pessoas, dentre alunos e professores dos cursos técnicos de enfermagem, os quais tiveram a oportunidade de esclarecer suas dúvidas sobre o quadro clínico, diagnóstico, tipos de terapias renais substitutivas e, principalmente, as formas efetivas de prevençáo da DRC.

Em decorrência da realização desse trabalho, houve a conscientização 
da populaçáo abordada, além de orientação e preparo ao aluno do curso técnico de enfermagem quanto à prevenção da doença renal crônica e promoção da saúde renal.

Os alunos participantes do projeto mostraram interesse e tiveram a oportunidade de retirar dúvidas e fazer questionamentos sobre o tema abordado.

É importante salientar que o futuro técnico de enfermagem tem um papel significativo na disseminação da informação e conscientização da populaçấo, visto que atuará nas diversas modalidades de assistência à saúde da comunidade, desde a atenção primária à saúde até o atendimento de alta complexidade.

Considerando o nível de discussão e questionamentos levantados na execução do projeto, pressupóe-se uma contribuição na formação do aluno como sujeito pensante e capaz de promover a saúde, construir conhecimento e atuar como multiplicador de informaçóes sobre a DRC junto à comunidade.

\section{CONSIDERAÇÕES FINAIS}

A ação extensionista relatada logrou êxito com a participação da quase totalidade de instituiçóes de ensino que oferecem curso técnico de enfermagem em Uberlândia. Os alunos foram ativos e empenhados na construção de conhecimento acerca do tema.

As acadêmicas envolvidas puderam enriquecer seus conhecimentos por meio da troca de saberes que a atividade proporcionou.

Espera-se que o projeto tenha propiciado a sensibilizaçáo e conscientização dos participantes com relação ao tema, para que possa haver a multiplicação dos conhecimentos entre os familiares e comunidade, além da aplicaçáo na prática assistencial enquanto futuros técnicos de enfermagem.

Por fim, acredita-se na importância do incentivo à realização de projetos de extensáo pelas universidades federais, os quais envolvem atividades que beneficiam tanto a sociedade quanto a comunidade acadêmica. 


\section{REFERÊNCIAS}

BASTOS, R. M. R. et al. Prevalência da doença renal crônica nos estágios 3, 4 e 5 em adultos. Revista da Associaçáo Médica Brasileira, São Paulo, v. 55, n. 1, p. 40-44, 2009. doi: http://dx.doi.org/10.1590/ S0104-42302009000100013.

BORBA, S. A.; MELO, É. G. A.; LELIS, R. F. Seja eficiente na prevenção da insuficiência renal. Em Extensáo, Uberlândia, v. 10, n. 2, p. 181-187, jul./dez. 2011. Disponível em: <http://www.seer. ufu.br/index.php/revextensao/article/view/20681>. Acesso em: 10 dez. 2017.

DUARTE, S. J. H.; BORGES, A. P.; ARRUDA, G. L. Açóes de enfermagem na educação em saúde no pré-natal: relato de experiência de um projeto de extensão da Universidade do Mato Grosso. Revista de Enfermagem do Centro Oeste Mineiro, Cuiabá, v. 1, n. 2, p. 277-282, 2011. doi: http://dx.doi.org/10.19175/recom.v0i0.13.

MIRANZI, S. S. C. et al. Perfil epidemiológico dos pacientes em hemodiálise de um hospital universitário. Revista Ciência, Cuidado e Saúde, Maringá, v. 10, n. 1, p. 110-115, 2011. doi: http://dx.doi. org/10.4025/cienccuidsaude.v10i1.10720.

RODRIGUES, T. A.; BOTTI, N. C. L. Cuidar e o ser cuidado na hemodiálise. Acta Paulista de Enfermagem, São Paulo, v. 22, p. 528-530, 2009. doi: http://dx.doi.org/10.1590/s010321002009000800015 .

RUDNICKI, T. Doença renal crônica: vivência do paciente em tratamento de hemodiálise. Revista Contextos Clínicos, São Leopoldo, v.7, n.1, p. 105-116, jan./jun. 2014. Disponível em: $<$ http://www.revistas.unisinos.br/index.php/contextosclinicos/article/ download/ctc.2014.71.10/4124>. Acesso em: 14 nov. 2017.

SCHMIDT, M. I. et al. Chronic non-communicable diseases in Brazil: burden and current challenges. The Lancet, London, v. 377, n. 9.781, p. 1.949-1.961, 2011. doi: http://dx.doi.org/10.1016/ s0140-6736(11)60135-9.

SESSO, R. C. et al. Inquérito brasileiro de diálise crônica 2013: análise das tendências entre 2011 e 2013. Jornal Brasileiro de Nefrologia, 
São Paulo, v. 36, n. 4, p. 476-481, Oct./Dec. 2014. doi: http://dx.doi. org/10.5935/0101-2800.20140068.

SCHREIDER, A.; FERNANDES, N. M. S. Avaliação do conhecimento sobre terapia renal substitutiva dos profissionais de saúde nas regiôes de Juiz de Fora, São João Nepomuceno e Santos Dumont. J. Bras. Nefrol. [online], São Paulo, v. 37, n. 3, p. 382384, 2015. doi: http://dx.doi.org/10.5935/0101-2800.20150059.

ZANQUETTA, D. et. al. Sistema Urinário. In: FIGUEIREDO, N. M. A.; VIANA, D. L.; MACHADO, W.C. A. (Coord.). Tratado prático de enfermagem. 2. ed. São Caetano do Sul, SP: Yendis, 2008. p. 270-271.

Submetido em 15 de dezembro de 2017.

Aprovado em 18 de abril de 2018. 